\title{
Brachyonychia Associated with Acroosteolysis in Chronic Kidney Disease: How Phalange Shape Influences Nail Morphology
}

\author{
José David Rosales Figueroa ${ }^{a}$ Patricia Chang ${ }^{b}$ \\ ${ }^{a}$ Centro Clínico Reforma, Ciudad de Guatemala, Guatemala; ${ }^{b}$ Hospital General de Enfermedades IGSS, \\ Ciudad de Guatemala, Guatemala
}

\section{Keywords}

Chronic kidney disease $\cdot$ Renal insufficiency · Brachyonychia · Racket nails · Transverse acroosteolysis · Longitudinal acroosteolysis - Radiographic changes of the phalanges . Nail morphology $\cdot$ Nails $\cdot$ Nail disease

\begin{abstract}
Brachyonychia is a rare manifestation in patients with chronic kidney disease. Longtime disease, secondary hyperparathyroidism, and hemodialysis are common conditions among those who present it. We evaluated 8 cases who presented brachyonychia in the nephrology department and compared the clinical versus the radiographic findings, and evaluated how the tissue adjusts to the underlying bone structure, giving different forms to the nails. We conclude that brachyonychia and acroosteolysis in chronic kidney disease suggest long-term disease, secondary hyperparathyroidism, and hemodialysis, besides it being a good model on how the bony structure defines the soft tissue morphology.
\end{abstract}

(c) 2018 S. Karger AG, Basel

Work performed at Instituto Guatemalteco de Seguridad Social (IGSS).

\section{KARGER}

(๑) 2018 S. Karger AG, Basel

E-Mail karger@karger.com

www.karger.com/sad
We reviewed 8 cases from patients with chronic kidney disease (CKD) undergoing hemodialysis treatment at the Nephrology Department of "Instituto Guatemalteco de Seguridad Social." These patients presented with brachyonychia and all of them had secondary hyperparathyroidism. The sample included 6 males and 2 females between 21 and 60 years of age (Table 1). Most patients had lived with the disease for more than 6 years. The parathyroid hormone (PTH) level was measured, with a lower obtained value of $429 \mu \mathrm{g} / \mathrm{mL}$ and a higher value of 2,611 $\mu \mathrm{g} /$ $\mathrm{mL}$. All patients had X-ray evaluation of the hands that showed acroosteolysis (AO) in the phalanges presenting with brachyonychia. Other findings were loss of interphalangic space, osteoporosis, osteonecrolysis, calcifications, and periosteal sclerosis in the metacarpi.

Nail dystrophy has been described as a sign of phalangeal osteolysis, since the function and shape of the nail unit is in part dependent on the underlying bone $[1,2]$. Clinically, nail dystrophy can present as pseudoclubbing, brachyonychia, koilonychia, pincer nails, and anonychia $[1,3,4]$.

Brachyonychia was described by DuBois in 1926 as an altered shape of the nail plate, which is short, broad, and flat, secondary to the deformity of the underlying bone and soft tissue of the terminal phalanges $[1,5,6]$. Two

Dr. José David Rosales Figueroa 
forms have been described: genetic and acquired. The former is believed to be secondary to changes in the cartilage, which could be obliteration, as proposed by Oluf Thomsen, or early closure of the cartilaginous line of the terminal phalanx, as proposed by Burrows [6].

According to Baran at al. [6], the principal cause for the acquired form of brachyonychia is hyperparathyroidism. This condition may be due to several causes including chronic renal failure, malabsorption, osteomalacia, and rickets $[6,7]$. Radiographic findings vary depending on the stage of the disease. At early stages, subperiosteal demineralization can be noted in the phalanges, followed by resorption of the terminal phalange, and finally $\mathrm{AO}$ [6].

AO describes the partial or total lytic destruction of the finger or toe phalanges, characterized by resorption of the bones $[2-4,8,9]$. It can be classified as primary or familial, idiopathic or nonfamilial, and occupational or secondary, as a consequence of several conditions. The most common causes being inflammatory diseases, sensory neuropathy, vascular disease, metabolic diseases, exposure to vinyl chloride, and trauma (Table 2) $[1,2,8-10]$.

There have been several physiopathologic mechanisms proposed for $\mathrm{AO}$, which vary in function with the base disease [11].

1. Vascular: (a) Occlusion and stenosis leads to bone infarction and resorption. This is secondary to elevated levels of cytokines like vascular end othelial growth factor. Osteoclast formation is also induced by hypoxia. $[1,12,13]$. (b) Vasodilatation increases blood flow (hyperemia), which in turn elevates oxygen partial pressure, favoring modulation and activity of osteoclast, resulting in bone resorption. This has been proposed as the mechanism for cold induced AO [1].

2. Nervous phenomena: (a) Sensory neuropathy causes predisposition to physical or thermal trauma, resulting in osteolysis secondary to mechanical trauma [10]. (b) Autonomic neuropathy leads to vasomotor instability, leading to loss of vasoconstriction and hyperemia, which has been postulated as a mechanism for osteolysis [10, 12].

3. Metabolic: Mainly caused by abnormal levels in serum calcium, phosphate, PTH, and active vitamin D [14].

Radiographic appearance of phalangeal osteolysis can be divided into three groups: those with resorption of terminal tufts, resorption of the midportion of the phalanges, and those with periarticular resorption [8]. Only two variants orient the clinical manifestations: transverse variant of $\mathrm{AO}$ presents an osteolytic band in the midportion of the phalange preserving its base and tuft, whereas
Table 1. Patient study characteristics

\begin{tabular}{lllll}
\hline $\begin{array}{l}\text { Case } \\
\text { number }\end{array}$ & Sex & $\begin{array}{l}\text { Age, } \\
\text { years }\end{array}$ & $\begin{array}{l}\text { Fingers } \\
\text { affected }\end{array}$ & $\begin{array}{l}\text { Time on } \\
\text { hemodialysis, } \\
\text { years }\end{array}$ \\
\hline 1 & M & 44 & thumbs, index & 5 \\
2 & M & 50 & whole hand, R and L & 7 \\
3 & M & 57 & thumbs & 15 \\
4 & M & 56 & whole hand, R and L & 24 \\
5 & F & 26 & 1, 2, 3, 5, R and L & 8 \\
6 & M & 35 & 1, 2, and 3 & 3 \\
7 & M & 21 & whole hand, R and L & 16 \\
8 & F & 29 & whole hand, R and L & 10 \\
\hline
\end{tabular}

$\mathrm{R}$, right; L, left.

Table 2. Mechanism of acquired acroosteolysis in related diseases

\begin{tabular}{ll}
\hline Mechanism & Diseases \\
\hline Vascular & $\begin{array}{l}\text { Vascular occlusion } \\
\text { a. scleroderma } \\
\text { b. diabetes mellitus } \\
\text { Frostbite }\end{array}$ \\
\hline Nervous & Diabetic mellitus \\
& Leprosy \\
\hline Metabolic & Hyperparathyroidism \\
& Diabetes mellitus \\
\hline Inflammatory & Scleroderma \\
& Raynaud disease \\
& Psoriatic arthritis \\
& Juvenile chronic arthritis \\
Epidermolysis bullosa & Dermatomyositis \\
\hline Trauma & Mechanical trauma \\
& Burns \\
& Electricity \\
\hline Drugs & Phenytoin \\
& Ergot derivates intoxication \\
& Polyvinyl chloride exposure \\
\hline & Epidermal inclusion cyst \\
& Glomus tumor \\
\hline & \\
\hline &
\end{tabular}

those with tuft resorption present a pencil-like pattern, also known as longitudinal AO [1,4] (Fig. 1).

CKD is associated with several skin and nail manifestations, which increase according to duration and severity of the renal disease. Common manifestations are xe- 
Fig. 1. Brachyonychia in a patient with 16 years of CKD and 3 years of hemodialysis. Clinical (a) and radiographic (b) images. Longitudinal acroosteolysis (white triangles) (b). Brachyonychia secondary to transverse acroosteolysis (white arrows) in a patient on hemodialysis for 8 years $(\mathbf{c}, \mathbf{d})$. Also an osteophyte is seen (white-outline arrow) (d).
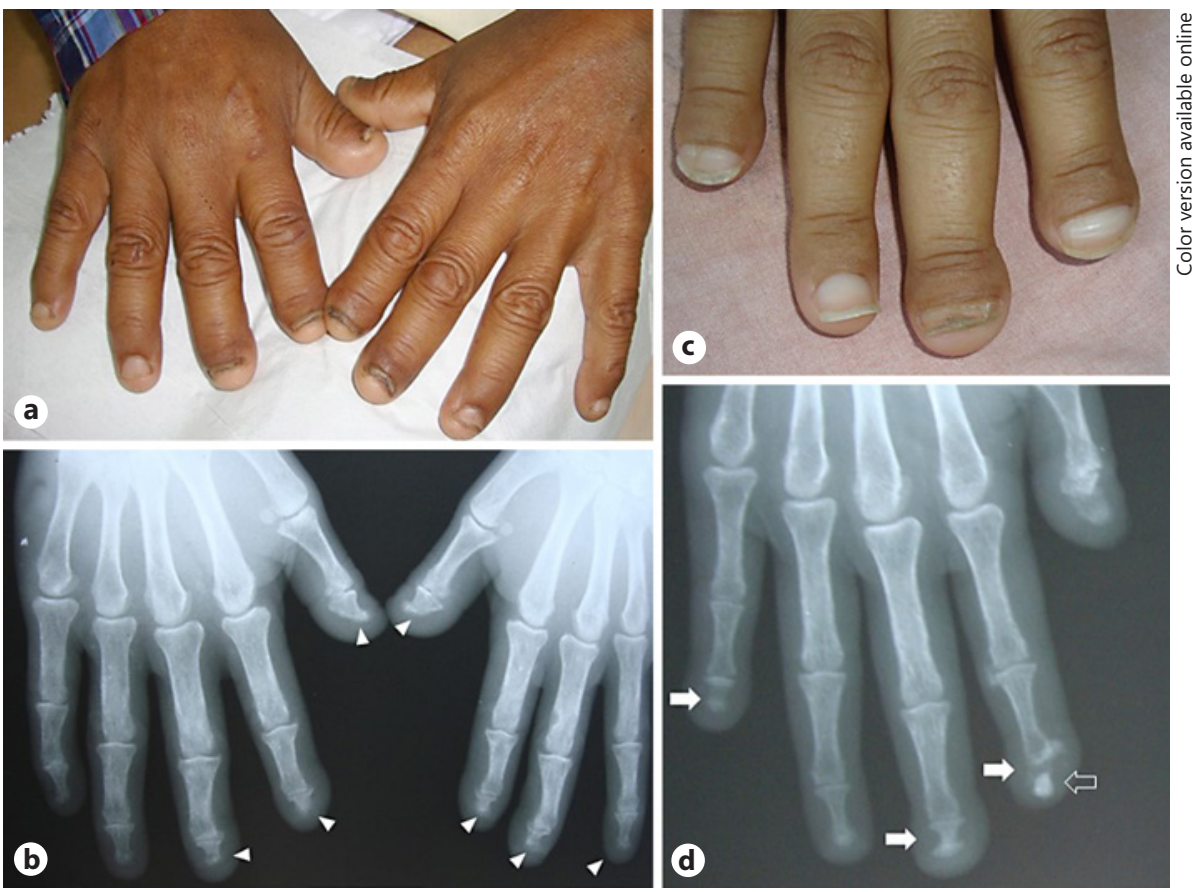

rosis, skin hyperpigmentation, pruritus, and nail changes [15-17]. Most nail changes in CKD appear or increase with dialysis and tend to disappear after kidney transplantation [15]. Nearly $70 \%$ of patients on dialysis have nail alterations such as half and half nails, splinter hemorrhage, or absence of lunula, among others [16, 17]. In Sakarya University, Turkey, 365 CKD patients were evaluated and $15.3 \%$ were found to have nail changes. However, there was no difference in the prevalence of nail changes between dialysis and non-dialysis patients, nor did they report any patients with brachyonychia [18]. According to these findings, brachyonychia remains an uncommon feature of CKD.

Hyperparathyroidism due to parathyroid gland hyperplasia and autonomic secretion is proposed as the mechanism of AO in patients with CKD [19]. Since the bony structure of the nail apparatus determines some nail changes, it has been hypothesized that patients with chronic high levels of PTH experience brachyonychia [19].

Abnormalities in bone turnover are the result of hyperphosphatemia, negative calcium balance, insufficient active vitamin $D$, vitamin $D$ receptors, and calcium receptors, as well as the proinflammatory state in patients with CKD. High turnover bone disease results from PTH levels higher than $400 \mathrm{pg} / \mathrm{mL}$, which induces osteoclastogenesis and a compensatory osteoblastogenesis. Yet there is also inhibition of osteoblast function and stimulation of osteoblast apoptosis with the end product of bone resorption $[14,20]$.

Patients with CKD also show resistance to vitamin D. It has been noted that supplementation with active vitamin D diminishes the activity of 25-hydroxylase and 1-alpha-hydroxylase enzymes, which are essential for endogenous formation of vitamin $\mathrm{D}$ forms, calcidiol and calcitriol, resulting in lower levels of vitamin $\mathrm{D}$ in the kidney as well as in extrarenal tissues. Lower bone formation and trabecular mineralization have been shown to occur in PTH in an independent manner. All of these changes lead to a significant loss in the mechanical integrity and toughness of cortical bone [14].

Cortical bone resorption has been noted as the primary mechanism of bone damage in CKD patients. The cortical bone suffers a decrease in its thickness, whereas trabecular bone thickness increases but has lower quality, signifying reduced trabecular connectivity and increased trabecular perforations [20].

\section{Conclusion}

Acquired brachyonychia is a rare nail morphology abnormality, most frequently seen in patients with hyperparathyroidism, a main cause of bone disease in CKD. 
This morphological change might be due to transverse AO secondary to hypertrophy of the phalange tuft, trabecular bone, which causes a broadening of the nail apparatus and the loss of the corresponding phalange midportion, or cortical bone, resulting in a shorter phalange. Similar and even more drastic nail changes are seen in advanced $\mathrm{AO}$, when the distal and midportions of the bone have been completely resorbed.

In longitudinal $\mathrm{AO}$, there is simply a thinning of the fingertip and nail plate giving a triangular appearance to the nail plate and fingers, reflecting the pencil-like radiographic findings.
According to this small series of cases, the shape of nails in CKD patients appears to suggest chronicity, high PTH levels, and an advance stage of the disease.

\section{Statement of Ethics}

All patients gave their informed consent about using their clinical information for educational studies.

\section{Disclosure Statement}

The authors declare no conflicts of interest.

\section{References}

1 El-Komy MH, Baran R: Acroosteolysis presenting with brachyonychia following exposure to cold. J Eur Acad Dermatol Venereol 2015;29:2252-2254.

2 Scher RK: Acro-osteolysis and the nail unit. Br J Dermatol 1986;115:638-639.

-3 Melenotte C, Rossi P, Reynaud GM, Harlé J, Aissi K, Frances Y, et al: Une dyspnée et des phalanges raccourcies. Rev Med Interne 2013; 34:785-786.

4 Graille J, Barry MB, Drapé JL, Doutre MS, Cogrel O: Acro-ostéolyse transversale: une cause rare d'onychopathie. Ann Dermatol Venereol 2016;143:284-288.

5 Fairris GM, Rowell NR: Acquired racket nails. Clin Exp Dermatol 1984;9:267-269.

-6 Baran R, Turkmani MG, Mubki T: Acquired racquet nails: a useful sign of hyperparathyroidism. J Eur Acad Dermatol Venereol 2014; 28:254-259.

7 Rasi A, Soltani-Arabshahi R, Naraghi Z: Circumscribed juvenile-onset pityriasis rubra pilaris with hypoparathyroidism and brachyonychia. Cutis 2006;77:218-222.

8 Datta P, Ghosh S, De A: Idiopathic non-familial acro-osteolysis: a rare case report. Indian J Dermatol 2012;57:486-488.
-9 Harzy T, Benbouazza K, Lazrak N, Amine B, Hassouni NH: Idiopathic phalangeal acroosteolysis: a case report. Joint Bone Spine 2003; 70:146-148.

10 Baer A, Zahr Z, Khan S, Polydefkis M: Acroosteolysis in diabetes mellitus. J Rheumatol 2012;39:2364-2365.

11 Weerakkody Y: Radiopaedia: Acro-osteolysis. 2015. Available from: https://radiopaedia. org/articles/acro-osteolysis-1.

12 Park J, Fava A, Carrino J, del Grande F, Rosen A, Boin F: Association of acroosteolysis with enhanced osteoclastogenesis and higher blood levels of vascular endothelial growth factor in systemic sclerosis. Arthritis Rheumatol 2016;68:201-209.

13 Johnstone E, Hutchinson C, Vail A, Chevance A, Herrick A: Acro-osteolysis in systemic sclerosis is associated with digital ischaemia and severe calcinosis. Rheumatology 2012;51: 2234-2238.

14 Lim CY, Ong KO: Various musculoskeletal manifestations of chronic renal insufficiency. Clin Radiol 2013;68:e397-e411.
15 Koduru S, Delhi N, Parvathina SN, Siva Kumar V: Cutaneous and nail changes in patients of chronic kidney disease: observations in a tertiary care unit from South India. Hemodial Int 2013;17:468-470.

16 Peres LA, Passarini SR, Branco MF, Kruger LA: Skin lesions in chronic renal dialysis. J Bras Nefrol 2014;36:42-47.

17 Tajbakhsh R, Dehghan M, Azarhoosh R, Haghighi AN, Sadani S, Zadeh SS, Kabootari M, Qorbani M: Mucocutaneous Manifestations and Nail Changes in Patients with EndStage Renal Disease on Hemodialysis. Saudi J Kidney Dis Transpl 2013;24:36-40.

18 Solak B, Acikgoz SB, Sipahi S, Erdem T: Cutaneuos findings in patients with predialysis chronic kidney disease. J Eur Acad Dermatol Venereol 2016;30:1609-1613.

19 Chang P, Roman Toro V, Osorio H: Braquioniquia asociada a hiperparatiroidismo secundario por insuficiencia renal crónica. Reporte de dos casos. Dermatología Cosmética, Médica y quirúrgica 2006;4:289-291.

20 Zheng CM, Zheng JQ, Wu CC, Lu CL, Shyu JF, Ho HY, et al: Bone loss in chronic kidney disease: quantity or quality? Bone 2016;87: 57-70. 